\title{
La “división antigua” en la Nueva España: Humboldt y la historia cartográfica del orden territorial
}

\author{
The "old division" in New Spain: Humboldt and the \\ cartographic history of the territorial order
}

Víctor M. González Esparza*

\section{RESUMEN}

El presente trabajo analiza el orden territorial novohispano a partir de dos perspectivas complementarias: por un lado, el "giro espacial", en el sentido de analizar los mapas como representaciones, y, por el otro, la nueva historia del Derecho, en la que se estudia la "territorialidad" del poder. El eje del análisis se encuentra en lo que Humboldt llamó la “división antigua”, y que diera a conocer más claramente Edmundo O'Gorman, la que incluía a las diferentes provincias que se fueron conformando desde los inicios de la colonización. Una división que sería representada hasta Humboldt en su "Carta Geográfica General de 1804", recientemente descubierta, por lo que la pregunta clave es por qué los científicos e ingenieros españoles y criollos no representaron esta "división antigua" de manera integral, a diferencia de los cartógrafos de las potencias europeas enemigas. Las respuestas se vinculan con los silencios o las "prácticas de reserva" de la Monarquía compuesta, pero también con la territorialidad que se inició desde los procesos mismos de colonización y que dependía de una visión plural y fragmentada del poder.

\section{ABSTRACT}

This paper analyzes the Novo-Hispanic territorial order from two complementary perspectives: on the one hand, the "spatial turn,"
Palabras clave:

Humboldt, Edmundo O'Gorman, división antigua, giro espacial.

Keywords: Humboldt, Edmundo

\footnotetext{
* Mexicano. Doctor en Estudios Latinoamericanos, Profesor Investigador, Departamento de Historia, Universidad Autónoma de Aguascalientes, México. E-mail: vicmago0421@gmail.com

El autor agradece a los editores y lectores anónimos de esta revista por sus valiosas sugerencias.
} 
in the sense of interpreting maps as representations, and, on the other hand, the new history of law, in which we study the "territoriality" of power. The basis of the analysis is found in what Humboldt called the "old division," made more widely known by Edmundo O'Gorman, which included the different provinces formed from the beginnings of colonization. A division factored until Humboldt in his recently discovered "General Geographic Chart of 1804". Hence, the critical question is why Spanish and Creole scientists and engineers did not represent this "ancient division" in an integral way, unlike the cartographers of the enemy European powers. Answers are linked to the silence or "reserve practices" of the Monarchy and territoriality that began with colonization and depended on a fragmented and plural vision of power.
O'Gorman, ancient division, spatial turn. 
“Los mapas no sólo replican, construyen y proyectan espacios, y así hacen de espacios territorios por vez primera."

KARL SCHLÖGEL, EN EL ESPACIO LEEMOS EL TIEMPO...

En un ensayo historiográfico sobre Humboldt en la Nueva España, Pietschmann se preguntó qué tanto conoció el científico explorador sobre este reino, más aún hasta dónde fue historiador, en el sentido de pensar el poder no centralizado sino desde pueblos, villas y ciudades, o de reflexionar sobre los conceptos mismos de reinos o provincias. Sin embargo, como bien reconoce el historiador alemán, Humboldt procuró, para su Ensayo político sobre la Nueva España, tener una imagen geográfica y física del reino, es decir, que se estudiaran los mapas que acompañan algunas ediciones, incluso antes de la lectura del Ensayo. De ahí que en los últimos años se haya renovado el interés sobre la obra de Humboldt, cuando es cada vez más clara la relación entre historia y geografía (Pietschmann, 2011).

El estudio de la cartografía ha sufrido una revolución epistemológica al pasar de las cuestiones sobre la calidad de las mediciones, sin duda necesarias, a lo que se ha dado en llamar el "giro espacial", y observar a los mapas como imágenes, como representaciones, lo cual ha permitido ampliar la imaginación geográfica. Los mapas han dejado de ser recursos auxiliares para la historia y se han convertido en "tiempo contenido", en arte, en paisajes y espacios imaginarios, en expresiones e instrumentos de poder, $y$, en ese sentido, han sido estratégicos por lo que muestran, pero también por lo que ocultan. Si los mapas representan un territorio, por los espacios que dibujan y también por lo que silencian e imaginan, son imágenes que pueden leerse a partir de la descripción técnica, pero también de los contextos que les dan sentido. Quizá por ello Harvey utilizó la iconografía y la iconología para la renovación de la historia de la cartografía, como otros autores han utilizado la "cultura visual" para analizar los mapas (Dym, 2010; Harley, 2005; Schlögel, 2003; Soja, 2010).

A partir de esta perspectiva, observar la historia del ordenamiento territorial, en particular novohispano, puede ayudarnos a comprender el proceso de "territorialidad", en el sentido de cómo es que, históricamente, se fueron construyendo las divisiones territoriales como formas de apropiación y control de espacios por grupos de poder, a partir 
fundamentalmente de la colonización desde el siglo XVI. Han existido diferentes propuestas de análisis (Antochiw, 2000; Moncada Maya, 2009), sin embargo, el objetivo del presente trabajo es reflexionar sobre la historia de las divisiones territoriales, teniendo en cuenta los olvidos de una división en particular que Humboldt llamó la "división antigua".

Escribir algo sobre Humboldt puede correr el riesgo de repetir lo ya dicho; sin embargo, a la "división antigua" mencionada por Humboldt no se le ha prestado la suficiente atención y, desde nuestra perspectiva, es una sugerencia fundamental para entender el origen de la división territorial novohispana, al igual que de la nación independiente. Por otra parte, como veremos, la imagen de esa división, que incluía las provincias, no fue dada a conocer por la Monarquía católica, no obstante que fue al menos descrita por López de Velasco en 1575, por razones estratégicas (prácticas de reserva de no dar a conocer las riquezas especialmente de la Nueva España). Al mismo tiempo, esa "división antigua" no se conocería hasta Humboldt por una concepción de "antiguo régimen" sobre la territorialidad, en la que el territorio estaba vinculado al poder de los capitanes de guerra y de los señores ricos que conformaron la ocupación del espacio, gracias a los privilegios y mercedes otorgados por la corona, lo que también muestra un especial orden jurídico y político (Del Vas Mingo, 1999; Garriga, 2004; Hespanha, 1993).

La organización del espacio político o del territorio ha estado vinculada, en términos historiográficos, a la conformación de los Estados nacionales, a la idea de una racionalidad del poder construida por la burguesía con base en el establecimiento de las fronteras, en la integración del mercado nacional y en la unidad cultural. En esta racionalidad estatista los regionalismos han sido vistos como negativos, como parte de los corporativismos tradicionales y de los residuos de intereses egoístas y oligárquicos, "como un signo de retraso que testimonia una mentalidad prerracional" (Hespanha, 1993).

Como bien lo señalaran Brunner y Hespanha, el espacio original es la casa, en la que un grupo de personas es conducido por un paterfamilias, las cuales están vinculadas más por una comunidad de vida que por lazos económicos o de sangre (Brunner, 1976; Hespanha, 1993). Se trata de una territorialidad en la que se encuentran integrados el espacio, el derecho de paterfamilias, la comunidad y las estructuras políti- 
cas "premodernas" o "antiguas", de tal manera que el territorio es parte fundamental del sistema de poder. Los pueblos, las villas, las ciudades, las provincias, los reinos y la monarquía son parte de este sistema cuya base es la Oeconomia, la idea de una comunidad gobernada por un padre virtuoso, piadoso y justo, encargado de armonizar las diferentes jurisdicciones que han mantenido su autonomía.

Por otra parte, este sistema antiguo se caracterizaba por la fragmentación política, dado que la estructura administrativa y burocrática era una concesión patrimonial hacia parientes y amigos, lo cual acentuaba la "miniaturización del espacio político", como lo llama Hespanha. Al unirse comunidad y territorio por varias generaciones, se da una rigidez en términos culturales, de tal manera que la división político-administrativa implica identidad de una "patria chica", pero también resistencia a cambios en la conformación espacial. De ahí la "territorialización del poder", es decir, que los vínculos políticos estén mediados por el territorio, más aún, "son las estructuras espaciales las que configuran política y jurídicamente a los individuos” (Hespanha, 1993: 102).

A diferencia de la planeación racional de los Estados modernos, para la que toda territorialidad previa aparece como "desordenada", la conformación espacial de tipo antiguo, tanto de pueblos y villas como de provincias, se relaciona con la división realizada desde la comunidad y no desde el poder central. Las irregularidades de la división territorial, el traslape de diferentes jurisdicciones, la indefinición de fronteras, etc., se vincula precisamente con esta idea sobre el espacio político, en la que el poder y el territorio están unidos, en donde se da precisamente la "territorialidad" del poder (Carmagnani, 1984; Sack, 1991; Saquet, 2015).

La historiografía al respecto se ha desarrollado desde la historia del Derecho o de la geografía (Diego-Fernández Sotelo, 1998; Dym, 2010; Moncada Maya, 2009); sin embargo, no se encuentran estudios que integren ambas perspectivas. La visión del orden territorial previo a la conformación del Leviatán es fundamental para entender el proceso de territorialidad. Por su parte, la cartografía crítica se ha enfocado en la conformación de los Estados nacionales, sobre todo desde el siglo XIX, de tal manera que ambas perspectivas se complementan. Esperamos que este trabajo sea comprendido a partir de una visión amplia e integrada del orden territorial novohispano. 
Lo primero que ha llamado la atención en la historia de las divisiones territoriales en México es la "anarquía", lo "embrollado" de las divisiones geopolíticas (O'Gorman, 2000). Ciertamente, contrasta con la idea planeada, por ejemplo, con el proyecto de división territorial de Jefferson para los Estados Unidos, en 1783 (Schlögel, 2003), o con los proyectados por Orozco y Berra para el Segundo Imperio en 1865 (Commons, 1989). Reconstruir la historia de la territorialidad en la Nueva España puede ayudarnos a entender la historia de esta concepción política diferenciada, es decir, del orden político del cual partió la división territorial del antiguo régimen mexicano.

\section{La "división antigua"}

Se han escrito muchas páginas para reconocer la importancia de Alexander von Humboldt para el "redescubrimiento de América", en el sentido de que fue el primer explorador en ofrecer las imágenes y las descripciones más avanzadas, con las más novedosas herramientas y la perspectiva científica más integral de los territorios americanos por él visitados, especialmente a través de sus trabajos sobre Cuba, Nueva Granada, Perú y la Nueva España. Me refiero a las imágenes porque, a través de los dibujos de la naturaleza y de la cartografía, se observa claramente la relevancia de lo visual en toda la obra del científico. Y, junto con ello, frente a las visiones ilustradas de la "degeneración" y por lo tanto "inferioridad" de la naturaleza en Indias, la obra de este explorador/científico colocó a la historia de la Nueva España/México en una perspectiva global. Quizá por ello Humboldt es cada vez más cercano a nuestro tiempo.

No obstante, pocos autores han reparado en una sugerencia que el explorador/científico hiciera sobre las divisiones territoriales en la Nueva España. Como en otros temas, el estudio de Edmundo O'Gorman continúa siendo un referente fundamental al respecto. Escrito originalmente en 1937, advertía ya del "laberinto que constituye la embrollada historia de nuestra división territorial". Sin embargo, es sin duda el estudio que más claridad proporciona, no solo sobre el periodo independiente sino sobre las divisiones territoriales durante la Colonia. Plantea de hecho una de las diferencias centrales entre ambos periodos: "En la Colonia las provincias surgen como resultado de fenómenos históricos reflejados sobre el territorio y reclaman un reconoci- 
miento legal; en la república las entidades se crean o desaparecen por misterio de la ley". En la primera se trata de una necesidad de hecho, en la segunda de derecho (O'Gorman, 2000: 4).

O'Gorman menciona las diferentes divisiones durante el periodo colonial, las cuales se fueron conformando simultáneamente. La primera son las eclesiásticas, a su vez con tres diferentes divisiones: por jerarquía, por provincias de evangelización, y la división de los territorios por los tribunales del Santo Oficio. La segunda se relaciona con las divisiones judiciales-administrativas, que recaían básicamente en las audiencias, y, finalmente, con la administrativa fiscal, que correspondía a las provincias y posteriormente a las intendencias. Cada una tenía su propio orden y jerarquía, por lo que la historia de este periodo se vincula con los diversos y múltiples conflictos de jurisdicción.

Hay un punto que menciona O'Gorman que resulta fundamental para nuestra historia y que está relacionado con lo que Humboldt llamó la "división antigua", es decir, la división geopolítica conformada por las provincias. "Estas antiguas divisiones son todavía muy usadas en el país", comentó Humboldt después de mencionar los reinos y provincias y antes de mostrar las intendencias (Alejandro de Humboldt, 2002: 100). El "Mapa reducido" o general de la Nueva España, presentado por Humboldt tanto en el Ensayo político como en el Atlas Geográfico - en el que reconoce que difícilmente en los mapas europeos se ubicaba la ciudad de Guanajuato, al mismo tiempo que menciona que el situar adecuadamente los centros mineros "parece haber tentado la codicia de algunos colonos"-, presenta las divisiones de provincias internas e intendencias con las mediciones más exactas conocidas hasta ese momento (Alexander von Humboldt, 2003). Sin embargo, realizó otro mapa hasta hace poco dado a conocer - que elaboró para el conde de la Valenciana, a quien visitó en Guanajuato-, y del que se realizarían algunas copias con una visión más clara de los centros mineros y de las provincias. Sobre este hallazgo comentaremos más adelante (Manso Porto, 2008).

Las provincias son territorios diferenciados desde la conquista y colonización en el siglo XVI, y que "encontraron reconocimiento en la costumbre y en la ley”, como bien comentó O'Gorman. Menciona incluso, cosa que no hemos explorado suficientemente, que los conquistadores "hicieron suyas en muchos casos las grandes divisiones territoriales 
indígenas", por lo que se siguieron reconociendo como provincias los territorios que antes de la conquista formaban parte de los reinos de México, Michoacán o Tlaxcala. De ahí que se les otorgara el nombre de "reinos" a la Nueva España, a la Nueva Galicia y a Nuevo León, dada la relevancia de los asentamientos prehispánicos encontrados. Un Reino, en este sentido, comprendía varias provincias ya preexistentes, y simplemente los territorios provincianos fueron "determinados por la ocupación europea y señaladamente por la ocupación militar" (Borah, 1985; O'Gorman, 2000; Tau Anzoátegui, 2000). De hecho, también las gobernaciones, como la de Yucatán y Nueva Vizcaya, mantuvieron claramente una denominación militar hasta fines del periodo. Habría que recordar que las jurisdicciones provinciales se fundaron en privilegios y mercedes otorgados a los capitanes de guerra, particularmente en la conquista y colonización septentrional, por lo que este tipo de territorialidad implicó múltiples e interminables conflictos y litigios, situación que trataría de remediar la Ordenanza de Intendentes de 1786, pero que a final de cuentas terminaría traslapando una vez más a las viejas jurisdicciones. Incluso después de la independencia la división territorial de México se explica más por la "división antigua" que por la de la Intendencia o de los obispados, como han sugerido algunos historiadores.

De acuerdo con Humboldt, cito:

"Antes de introducirse en América el nuevo orden de administración dispuesto por don José de Gálvez, Ministro de Indias, La Nueva España comprendía: 1. El reino de México, 2. El reino de la Nueva Galicia; 3. El nuevo reino de León; 4. La colonia del Nuevo Santander; 5 . La provincia de Texas; 6 . La provincia de Coahuila; 7 . La de Nueva Vizcaya; 8. La de la Sonora; 9. La de Nuevo México y 10. Las dos Californias o provincias de la Vieja y Nueva California" (Alejandro de Humboldt, 2002: 99-100).

Además, como lo aclararía O'Gorman, cada reino y gobernación incluía diferentes provincias: 1 . El Reino de México, las provincias de México propiamente, Tlaxcala, Puebla de los Angeles, Antequera (Oaxaca) y Valladolid (Michoacán); 2. El Reino de Nueva galicia, las provincias de Xalisco o Nueva Galicia, Zacatecas y Colima; 3. La Gobernación de la Nueva Vizcaya, las provincias de Guadiana o Durango, y la de Chihuahaua; y 4. La Gobernación de Yucatán, con las provincias de Yucatán p.m.d., Tabasco y Campeche (v. Mapa 1) (O’Gorman, 2000: 14). 


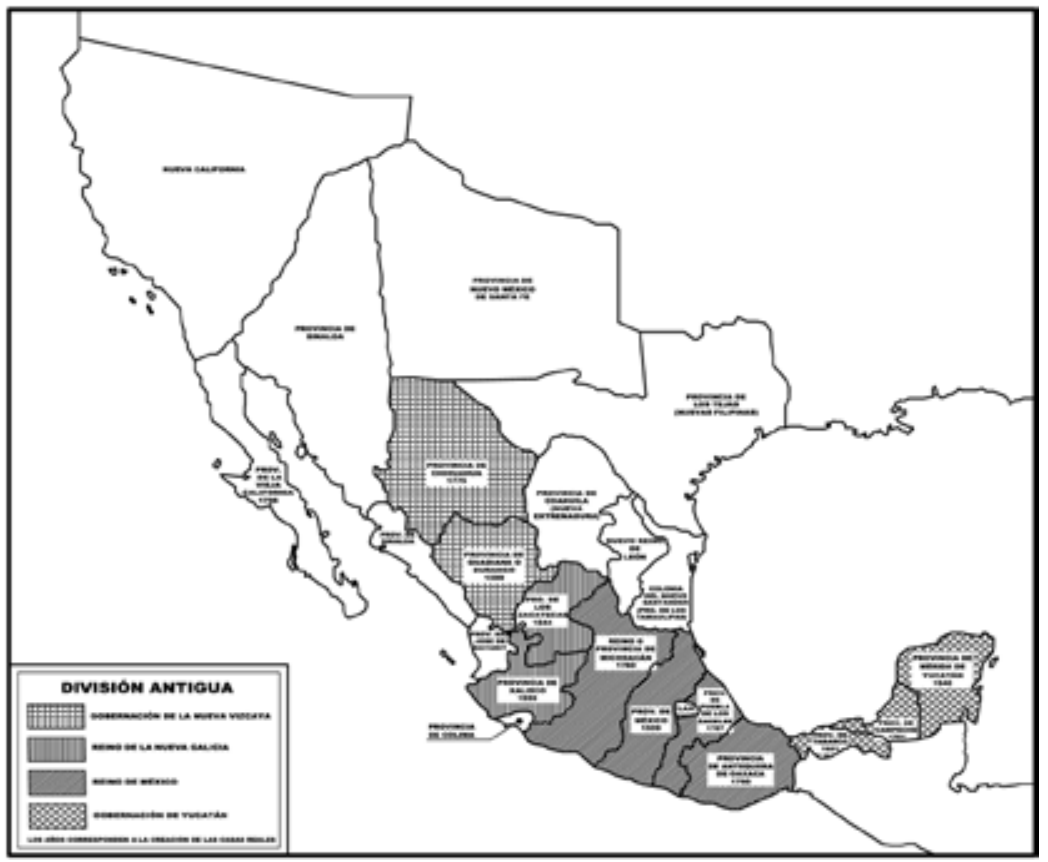

Figura $N^{\circ} 1$. Mapa de la "División Antigua”.

Fuente: Edmundo O'Gorman, Historia de las divisiones territoriales de México, Ed Porrúa, 9a. ed., 2000, pp. 16-17; reelaborado digitalmente por María González. Los años debajo de cada nombre de provincia son los años de creación de las cajas reales en cada capital, agregados por el autor de este ensayo.

La historiografía ha enfatizado las dificultades para llevar a cabo un Mapa general de la Nueva España, especialmente a partir de sus provincias, lo cual ha sido explicado por la estrategia de la Monarquía castellana, y luego borbónica, de mantener en secreto los principales centros mineros (Cramaussel, 1998; Hillerkuss, 2013). Se trató de "prácticas de reserva" que la Monarquía católica utilizó como política de seguridad frente a sus enemigos. De ahí que la principal preocupación cartográfica de la Monarquía fueran las costas, por lo que la mayor parte de los mapas y planos existentes en los archivos refieran a éstas, a puertos y bahías, penínsulas y fronteras, ríos y montañas que concluían en las costas, así como obispados o provincias por separado, pero no de las provincias en su conjunto, con el detalle de tierra adentro (Antochiw, 2000; Buisseret, 2005; Moncada Maya, 2009; Reinhartz, 2005). 
Las primeras representaciones de las provincias no provienen de la Monarquía castellana sino de sus competidores europeos. Destaca, por ejemplo, la que fue llevada a cabo por el hidrógrafo de los reyes ingleses John Seller, en 1685, quien durante treinta años tuvo el monopolio de publicar los atlas navales de Inglaterra. Se trata de un mapa coloreado, pequeño en el formato ( $6 \times 4,5$ pulgadas), titulado "Mexico or New Spain" (v. Mapa 2). Incluye las provincias de Centroamérica, y todo el septentrión, después de la Nueva Vizcaya, es presentado como espacio vacío solo con el nombre de Florida, a diferencia del que realizaría Guillaume de la I'sle en 1700 - uno de los cartógrafos franceses más prolíficos- sobre la América septentrional, en el que aparecen también las colonias inglesas y francesas (León-Portilla, 2001). En el mapa de Seller aparece Zacatecas, pero no Guanajuato, como bien lo señalaría Humboldt. Habría que recordar que la falta de información difundida por la Monarquía castellana, por el temor de que se conociera la riqueza minera del septentrión y, por lo tanto, para retardar las ambiciones inglesas, francesas y holandesas principalmente, impidió que se llevaran a cabo mapas científicos de esta región de la Nueva España. En todo caso, muchos de los mapas elaborados presentaban un territorio prácticamente vacío, lo cual alimentó las ambiciones de las potencias enemigas de la Monarquía hispana (Cramaussel, 1998). 


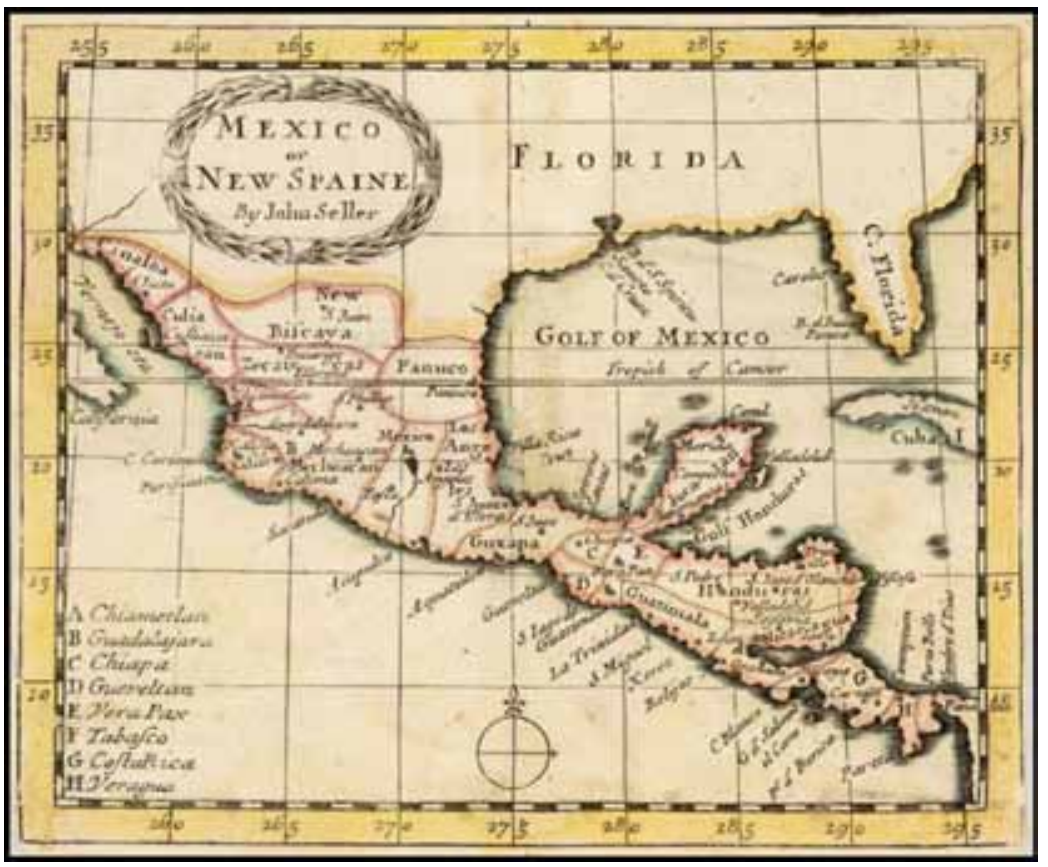

Figura $N^{\circ}$ 2. Mapa de John Seller “Mexico or New Spain” (1685).

Fuente: Miguel León-Portilla, Cartografía de la Antigua California (Ciudad de México : Universidad Nacional Autónoma de México, 2001), 136. Existe otro mapa muy similar al de John Seller, que fue el realizado por Robert Morden, "Mexico or New Spain" (1688), que se encuentra en el Museo Franz Mayer.

La inexactitud acerca de los centros mineros en los mapas europeos se constata nuevamente en uno de los mapas más completos sobre las provincias, con clara alusión también a las audiencias, el cual fue el realizado por Pieter van der Aa en 1714 ("Mexique ou Nouvelle Espagne") en su Nouvel Atlas, en Holanda. En este Mapa aparecen 15 provincias, sin contar las centroamericanas, y no aparecen las Californias ni Nuevo México. Hay un grabado en la parte inferior izquierda de este Mapa en el que aparece una suerte de conquistador hispano, con una pierna sobre los cuerpos arrodillados de un indio con corona y un esclavo negro, con un paisaje en donde abundan los ganados y la vegetación. En un Atlas difundido en inglés, con estas imágenes, no deja de ser parte de cierta propaganda. Las minas de Zacatecas y Guanajuato, por ejemplo, están bien señaladas. El autor tiene otro Mapa de la América septentrional en el que considera incluso las colonias francesas, "Canada ou Nouvelle France", pero sin las provincias de la Nueva España. Sin embargo, el de- 
dicado en específico a "Mexique ou Nouvelle Espagne" sigue siendo un referente importante en la reflexión acerca de las divisiones que, como hemos comentado, se originaron desde el siglo XVI con propósitos administrativos, territoriales/militares y fiscales. ${ }^{1}$

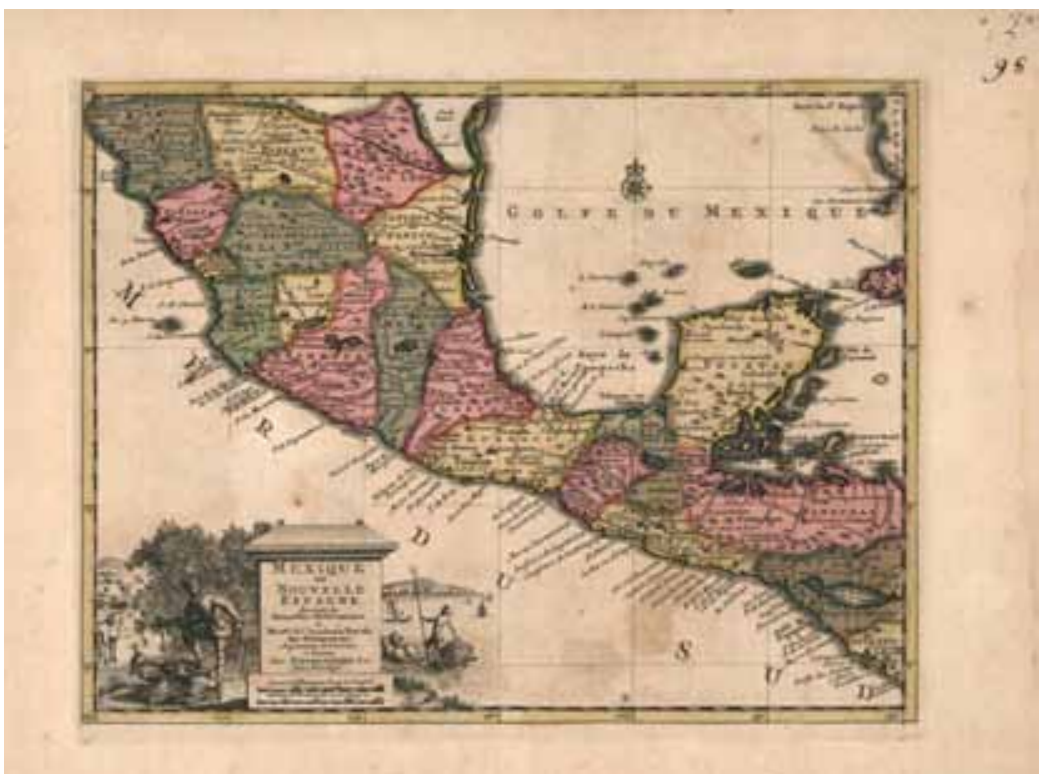

Figura $N^{\circ}$ 3. Mapa de Pieter Van der Aa “Mexique ou Nouvelle Espagne” (1714). Fuente: Pieter van der Aa, Nouvel Atlas, tres-exact et fort commode pour toutes sortes de personnes, Contenant les Principales Cartes Geographiques. (Leiden : Phillips, Geographical Atlases, Vol. IV, title 4277, 1714), 98. En David Rumsey Historical Map Collection, https://www.davidrumsey.com/luna/servlet/detail/RUMSEY 8 1 297 959 90069515?qvq=w4s\%3A\%2Fwhere\%2FMexico\%3Bq\%3AMexico\%3Bsort\%3AP ub_Date\%2CPub_List_No_InitialSort\%3Blc\%3ARUMSEY 8 1\&mi=27\&trs=937\# consultado el 20-X-2020.

Eman Bowen (geógrafo de su Majestad, cartógrafo, impresor y publicista inglés), en 1752, realizó otro mapa bellamente coloreado y con un grabado copiado del conquistador realizado originalmente por Pieter van der Aa. Esta imagen sería constantemente repetida, sin duda parte de la propaganda antimonarquía católica. Incluye bien las minas de Zacatecas, pero, nuevamente, no las de Guanajuato. Contiene 18 pro-

1 De la parte inglesa, otro de los mapas, divulgado con las provincias, fue el de Aaron Arrowsmith. "Chart of the West Indies and Spanish Dominions in North America" (London: A. Arrowsmith, first edition, 1803). 
vincias, incluidas California, Nuevo México, Luisiana y Florida, pero con cambios en grados en las ubicaciones. Se trata de un excelente ejemplo de representación de las provincias de mediados del siglo XVIII.

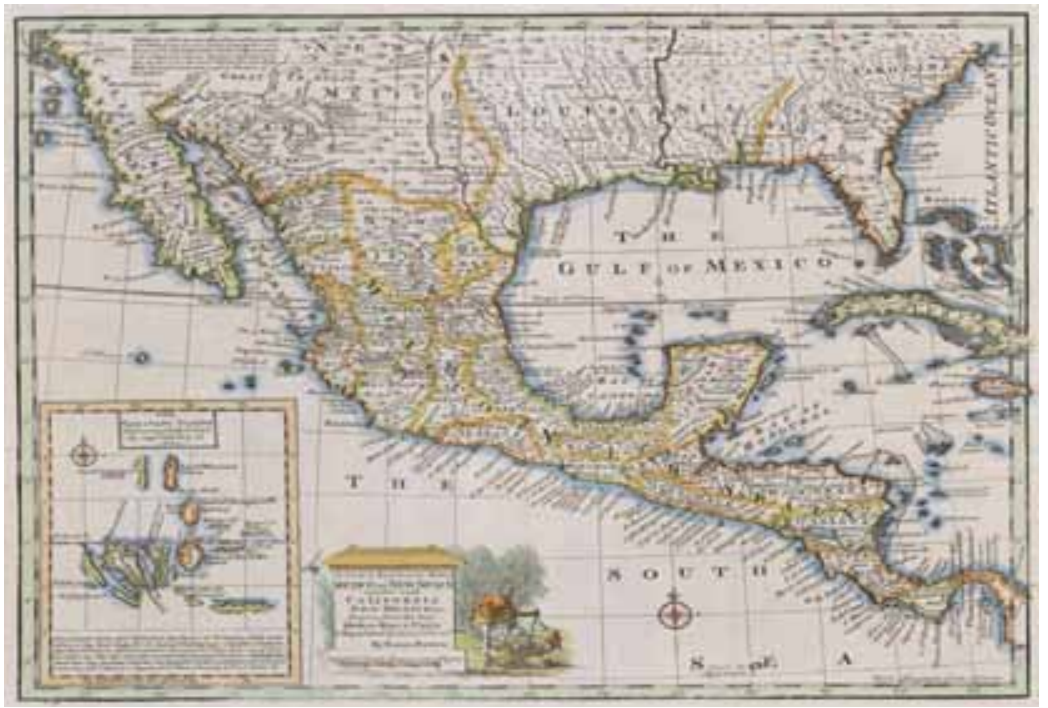

Figura $N^{\circ}$ 4. Mapa de Eman Bowen "A New \& Accurate Map of Mexico or New Spain (1759).

Fuente: Eman Bowen "A New \& Accurate Map of Mexico or New Spain together with California, New Mexico" (1759), University of Texas at Arlington.

Ahora bien, ¿por qué la inexistencia de un mapa general de las provincias de la Nueva España y Nueva Galicia por parte de los geógrafos españoles o novohispanos? Juan López de Velasco, el cosmógrafo y cronista real de Felipe II, redactó su Geografía y Descripción Universal de las Indias entre 1571 y 1574; sin embargo, esta obra fue publicada hasta 1894 (López de Velasco, 1894). En ella, además de considerar la descripción administrativa desde el Consejo de Indias y de las audiencias, incluyó las "divisiones espirituales", como llamó a la del arzobispado y obispados, pero muy claramente también incluyó a las diferentes provincias, tanto de los reinos y audiencias de México, como de Nueva Galicia, así como audiencias de Santo Domingo, Guatemala, Panamá, del Nuevo reino de Granada, del reino de Perú, de la Audiencia de Quito, de los Reyes, de Charcas, e incluso las provincias, tanto del Río de la Plata como del Brasil. Además, incluyó descripción de las costas de China, de Nueva Guinea y de las islas Salomón. Sin duda, para su mo- 
mento, se trató de una visión global de los dominios de la Monarquía hispana, la cual deja ver que está estructurada en provincias.

Lamentablemente su obra no contiene mapas, quizá, como sugirió Jean-Pierre Berthe, por las "severas críticas" que le hiciera Juan Bautista Gesio, cosmógrafo y matemático napolitano e informante de Felipe II, particularmente por las deficiencias geográficas y matemáticas del manuscrito (Berthe, 1998). ${ }^{2}$ Así, no obstante, o quizá gracias a la ambición de la obra de López de Velasco, incluye una de las descripciones más tempranas y completas de las provincias. Ciertamente, una buena edición crítica de su obra, así como la elaboración de los mapas que sugiere, sigue pendiente (Berthe, 1998).

Después de esta obra de López de Velasco se llevarían a cabo descripciones y representaciones de algunas provincias, la mayoría realizadas por separado, quizá como ejemplo mismo de la manera policéntrica en que se gestionaría la territorialización y el ejercicio de gobierno por parte de la Monarquía. En la obra Política indiana (1647), de Solórzano Pereira, va a predominar igualmente la palabra provincia $\mathrm{y}$, al formar parte de la Monarquía castellana, los reinos o provincias nuevos se unen accesoriamente a otros antiguos, por lo que se regulan por las mismas leyes. De tal manera, como comenta Tau Anzoátegui, se aplica la doctrina del Derecho común, con el fin de proveer soluciones adecuadas a las nuevas situaciones que se presenten. Lo accesorio no implicó necesariamente una mayor subordinación, sino una mejor integración a Castilla, lo cual creó una relación compleja y ambigua con la Corona, pero con reinos y provincias con gran autonomía, con instancias descentralizadas y, también, con grandes privilegios a la elite criolla (Annino, 2015; Cardim et al., 2014; Tau Anzoátegui, 2000).

Como se sabe, la construcción de los primeros mapas "científicos" se debe a Sigüenza y Góngora, en el siglo XVII, y a Alzate en el siglo XVIII. Habría que incluir también el hidrográfico de Villaseñor y Sánchez realizado en 1746. Para algunos tratadistas, entre ellos Humboldt, el mapa

2 La crítica de J. B. Gesio que se conserva sobre el manuscrito de López de Velasco Demarcación y división de las Indias (Biblioteca Nacional de España, 1580), una síntesis de la Geografía Universal que contenía algunos mapas, dice: "he hallado que este libro no está compuesto según los preceptos de la Geografía, y contener casi nada de esta Sciencia, y por este no ser libro Geográfico, sólo ser una abreviación de Historia y comentario...," citado en Berthe, 1998. 
de Alzate es una copia del de Sigüenza y Góngora, no obstante que pocos conocieron el elaborado por este último sabio. Como bien lo señalaron Sánchez Lamego y Elías Trabulse, más allá de las imperfecciones técnicas la obra cartográfica de Sigüenza y Góngora fue fundamental, al grado que su mapa permaneció hasta la recuperación que hiciera Alzate (Antochiw, 2000; Codding, 1994; Sánchez Lamego, 1955; Trabulse, 2001).

Al trabajo de Villaseñor y Sánchez habría que reconocerle la identificación, como lo hiciera Sigüenza y Góngora, de los principales ríos y lagunas del territorio novohispano. Está dividido por obispados y jurisdicciones menores, con la descripción de ciudades, villas y pueblos, no obstante que su título incluye "Reinos y provincias de Nueva España". Su fuente fueron las relaciones geográficas que, en el siglo XVIII, mandó realizar la Corona de los diferentes pueblos, villas, ciudades, provincias y reinos. No obstante, la división basada en las provincias se mantuvo en silencio (Villaseñor y Sánchez, 1992).

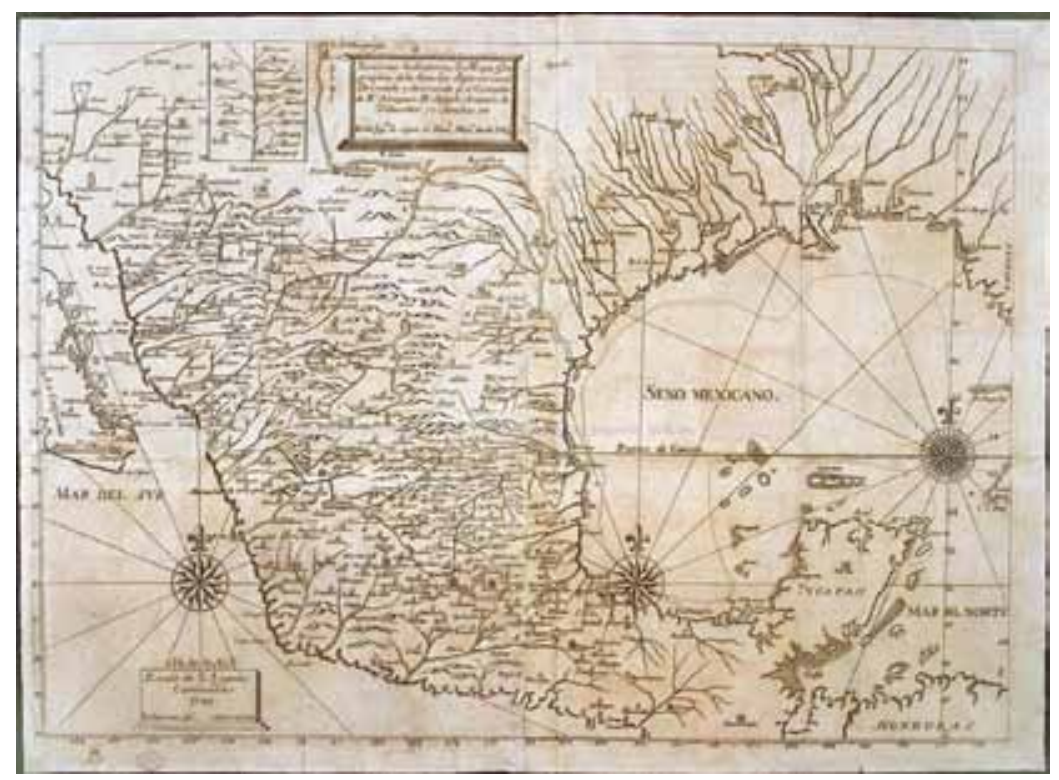

Figura $N^{\circ}$ 5. Villaseñor y Sánchez, Mapa Geographico de la América Septentrional (1746).

Fuente: Archivo General de Indias, MO-MEXICO, 161, fecha 1746. "Yconismo hidrotérreo, o Mapa Geográphico de la America Septentrional. Delineado y observado p[o]r el Contador de los R[eale]s Azogues D[on] José Antonio de Villaseñor y Sánches". Mapa de la América septentrional, delineado por José Antonio de Villaseñor y Sánchez y grabado por Francisco Sylverio de Sotomayor. Consultado en http://pares.mcu.es/ParesBusquedas20/catalogo/show/20997 el 10-XI-2020. 
Alzate mantuvo la división en obispados (Figura $\mathrm{N}^{\circ}$ 6), con el argumento de que "un alcalde mayor por razón de que así lo establecen las leyes, poco tiempo reside en un mismo territorio, y por consiguiente no puede tener aquella instrucción topográfica que poseen los curas." (Trabulse 1983: 25). Es decir, los curas estaban mejor preparados para llevar a cabo las mediciones cartográficas. De hecho, el nombre que le dio la biblioteca en la que se encuentra el original de Alzate es el "Mapa del Arzobispado de México", dado que representa las divisiones eclesiásticas.

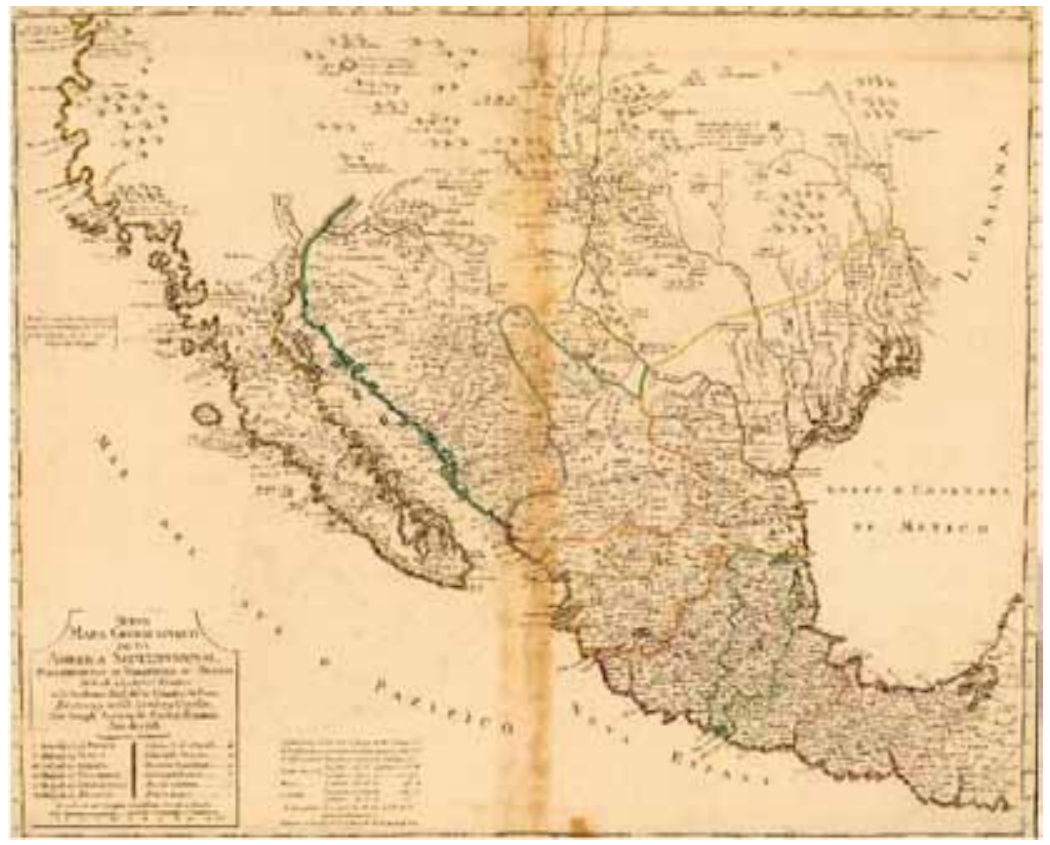

Figura $N^{\circ} 6$. José Antonio de Alzate, “Mapa del Arzobispado de México” (1768). Fuente: John Carter Brown Library, Brown University.

Pero la ausencia de un mapa con las divisiones civiles no puede explicarse solo porque para las autoridades políticas españolas nunca fue un "requisito insoslayable" contar con un mapa integrado; tampoco porque no existía el personal suficientemente preparado para llevarlos a cabo (Rojas, 1999). Este tipo de explicaciones sigue pensando la cartografía novohispana con visiones eurocentristas, ya que, como veremos, existió un centenar de ingenieros militares con excelentes trabajos cartográficos, como lo reconociera el propio Humboldt. Como hemos tratado de argumentar, dada las características del espacio público y de la 
Monarquía hispana, la cartografía respondió más a los intereses provinciales que del reino en su conjunto. Ello se manifestará claramente con las reformas borbónicas y con el movimiento autonomista/independentista generado por la invasión napoleónica en 1808, y en el Mapa de la “división antigua” sugerido por Humboldt y rescatado por O'Gorman.

Las reformas borbónicas son un excelente escenario para observar la integración de las antiguas divisiones con las nuevas "intendencias de provincia". La revisión reciente de dichas reformas ha destacado la transformación del virreinato (con varios reinos), en un solo Reino de la Nueva España, al mismo tiempo que destaca el papel jugado por las subdelegaciones en la nueva integración territorial a partir de las "intendencias de provincia" y de las provincias internas (Diego-Fernández Sotelo y Gutiérrez Lorenzo, 2014). Otra cuestión que queda clara también es que el proceso implicó centralización por el tipo de planeación, pero quizá más descentralización al fortalecer el papel de los subdelegados, por ejemplo, en cuestiones tributarias. Además, un aspecto clave en lo que hemos argumentado, en que las ordenanzas de intendentes prácticamente vendrán a legitimar el gobierno provincial. Poco se ha reparado, por ejemplo, en que a las intendencias se les llamó "de provincias", y en que a las provincias internas se les daría una reorganización con el fin de que contaran también con mayores atributos.

En términos cartográficos, la elaboración detallada del resultado del régimen de intendencias reafirma y potencia la división en provincias, concepto en el que habría que insistir. Incluso si se analiza el caso de la Intendencia de Guadalajara, habría también una correspondencia territorial con el Obispado de Guadalajara, lo que incorporaría a 17 alcaldías mayores y ocho corregimientos, 25 subdelegaciones en total (Diego-Fernández Sotelo y Gutiérrez Lorenzo, 2014; Mantilla Trolle, Diego-Fernández Sotelo y Moreno Torres, 2008: 25-27). Las reformas borbónicas lograron mantener las viejas divisiones a través de las “intendencias de provincias", además de intentar reorganizar los territorios septentrionales mediante las provincias internas. Los constantes cambios jurisdiccionales de finales del siglo XVIII de estas provincias internas muestran la poca definición de las fronteras y la inseguridad de estos territorios (Álvarez, 2011; Gerhardt, 1996).

Como comentamos al inicio de este apartado, Humboldt conoció la "división antigua" por las referencias que ofrece para su "Carta general 
de la Nueva España". De hecho, esta Carta representa a las provincias y a las intendencias de provincia, y muestra cómo se dio la integración territorial novohispana, origen de la división geopolítica nacional. Gracias a los acervos cartográficos de la Real Academia de la Historia de España, en especial de la Colección Humboldt que posee, y a la posibilidad de consulta digital que ofrece su portal, podemos revisar una copia digital de tan importante carta identificada recientemente (Manso Porto, 2008).

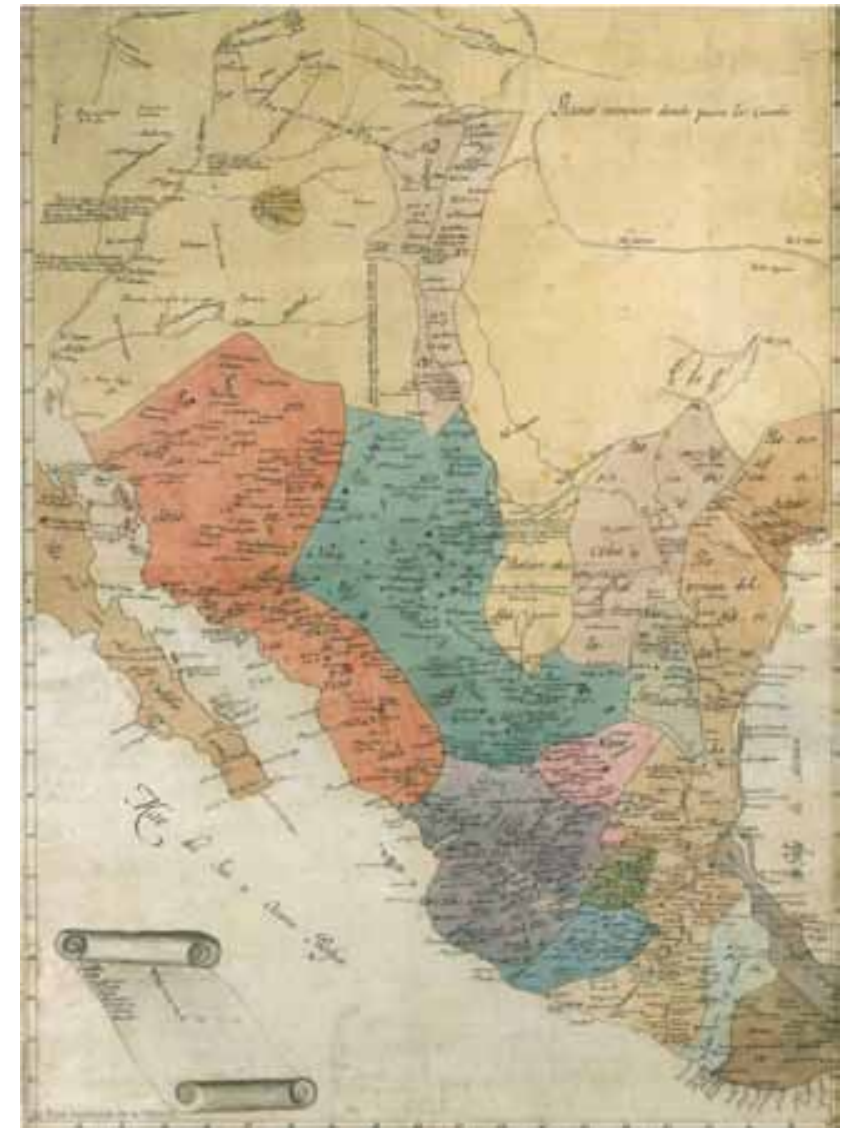

Figura $N^{\circ}$. Humboldt, Carta Geográfica general del reino de la Nueva España (1804).

Fuente: Real Academia de la Historia, "Carta geográfica general del reino de Nueva España, sacada de la original hecha en 1803 por el Sor. Barón de Humboldt y dedicada al señor conde de la Valenciana. Es una de las copias manuscritas coetáneas que se hicieron del original de Humboldt en la Ciudad de México en 1804", Consultado en: https:// bibliotecadigital.rah.es/es/consulta/resultados_navegacion.do?cadena_busqueda $=\mathrm{S}$ EC\%3A+6\&idTema=6\&idRoot=1\&id=57727\&forma=ficha\&posicion=4 el 10-XI-2020; v. (Manso Porto, 2008) 
De acuerdo con el propio Humboldt, para la elaboración de la Carta General consultó 36 mapas o cartas, y entre las más destacados, que ofrecen una visión general de la Nueva España, fueron el Mapa manuscrito de la Nueva España, realizado por Costanzó y Mascaró (ca.1779), al igual que el Mapa general de la Nueva España, también por Costanzó, "precioso por el conocimiento de las costas de Sonora"; el Mapa del Arzobispado de México (1772), por José Antonio de Alzate, "es muy malo", comentó lacónicamente Humboldt; el de Velázques, de 1772, Mapa manuscrito de toda la Nueva España; el de Antonio Forcada y la Plaza, de 1787, Mapa manuscrito de todo el reino de Nueva España; y el de Carlos Urrutia, Mapa manuscrito de una parte de la Nueva Espa$\tilde{n} a . . .$, ordenado por el virrey Revillagigedo (Antochiw, 2000).

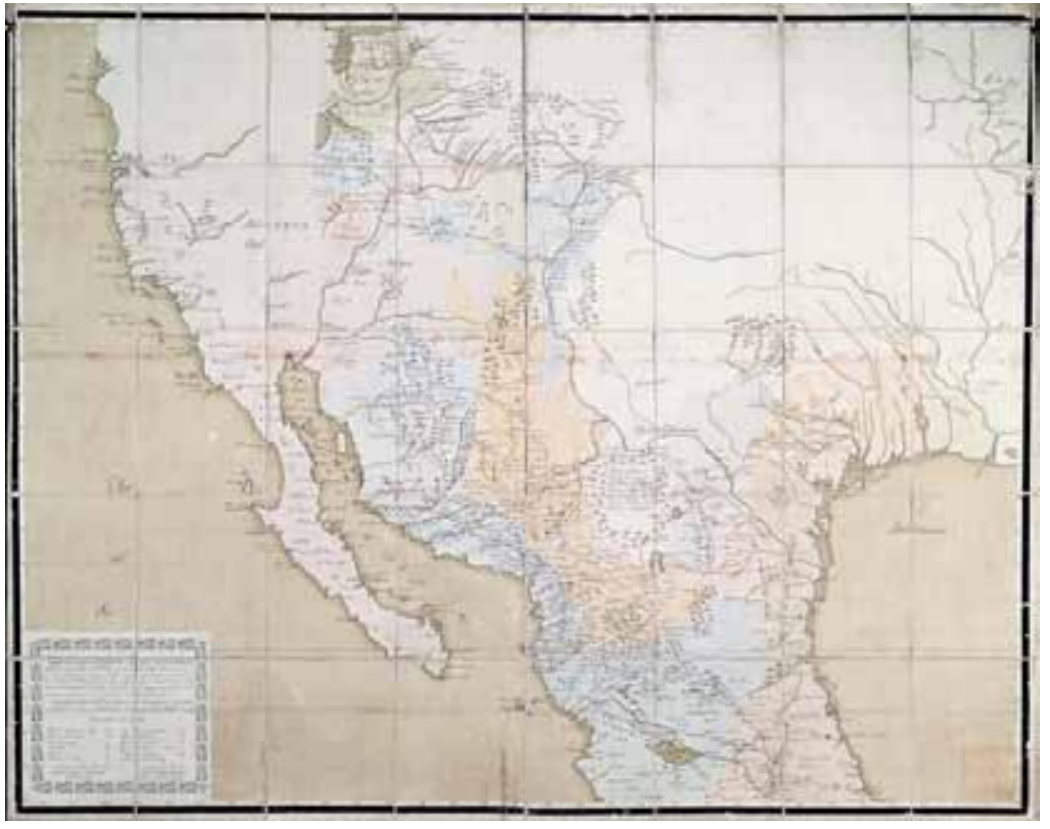

Figura $N^{\circ}$ 8. Costanzó y Mascaró, “Carta o Mapa Geográfico de una gran parte del Reino de N.E..." (c1779).

Fuente: Archivo General de Indias, MP-MEXICO, 346: “Carta ó Mapa Geográfico de una gran parte del Reino de N. E. [Nueva España], comprendido entre los 19 y 42 grados de latitud Septentrional y entre 249 y 289 grados de longitud del Meridiano de Tenerife, formado de orden del Exc[elentísi]mo S[eño]r B[eilí]o Fr[ey] D[o]n Ant[oni]o Maria Bucarely y Vrsúa p[ar]a indicar la division del Virreinato de México y de las Provincias internas erigidas en Comandancia General en virtud de Reales Órdenes el año 177". Nota de autoría: "Construyólo el Ingeniero D[o]n Mig[ue]l Constansó y va aumentado con varias noticias que adquirió en sus viages a d[ic]has Provincias el Ingeniero Ordinar[i]o D[o]n Man[ue]l Mascaró". Consultado en http://pares.mcu.es/ParesBusquedas20/catalogo/show/21214 el 3-XI-2020. 
La obra de cerca de un centenar de ingenieros militares españoles asentados en la Nueva España ha sido bien valorada en varios estudios (Buisseret, 2005; Moncada Maya, 2009; Reinhartz, 2005), en particular la de Miguel Constanzó, destacando su contribución como ingeniero/ arquitecto (diseñó entre otros edificios la Ciudadela) y, desde luego, como cartógrafo. Humboldt mantuvo correspondencia con Constanzó y siempre le reconoció sus aportaciones a la cartografía novohispana. Por ejemplo, respecto del Mapa realizado conjuntamente entre Constanzó (que Humboldt refiere Costansó...) y Mascaró, quienes trabajaron en varios proyectos conjuntamente, Humboldt escribió: "Parece trabajo hecho con mucho esmero...”; también se refirió a él como

"Este sabio, tan modesto como profundamente instruido, ha recogido de treinta años a esta parte cuanto tiene relación con el conocimiento geográfico del extenso reino de Nueva España. Es el único oficial de ingenieros que se ha dedicado a examinar profundamente las diferencias en longitud de los puntos más lejanos de la capital (...) Yo tengo tanta mayor satisfacción en tributar esta justicia al señor Constanzó (...)" (Moncada Maya, 2009: 170).

La referencia es importante, ya que medir las escalas, especialmente de longitud, fue uno de los grandes hallazgos científicos de la segunda mitad del siglo XVIII, lo cual ofrece una idea de la actualidad científica novohispana en general a partir de la cartografía (Trabulse, 1983).

Como hemos tratado de mostrar hasta aquí, de acuerdo con la tradición de la Monarquía castellana, a través de las audiencias y las provincias con sus ciudades capitales, el orden político estuvo estructurado con base en la administración de justicia por parte de los jueces y no en las leyes, de tal manera que la soberanía recaía en la territorialidad construida a partir de los distritos audienciales, de las capitales de provincia y de las repúblicas de los pueblos de indios. La expresión de esta territorialidad, "revolución territorial" le llamó Annino, ocurriría a partir de la representación de las diputaciones provinciales, pero también de la multiplicación de las municipalidades, de tal manera que la soberanía se reprodujo "originalmente" en la nación, pero también en las provincias que dieron origen a los estados de la república, y en los miles de cabildos que se crearon a partir de la carta de Cádiz, creando así un conflicto estructural de soberanías en conflicto (Annino, 2015). 
Ello ciertamente dificultaría el nuevo orden político hasta bien entrado el siglo XIX.

El mapa que expresará con claridad la importancia de las divisiones en provincias internas e intendencias de provincia sería el publicado por John Melish en Filadelfia, el año de 1820. Melish analiza la extensión de cada provincia y su población, así como la extensión de las provincias internas y prácticamente el despoblado entre las posesiones estadounidenses y españolas. Quizá por ello era el silencio de la Monarquía hispana, no solo por el temor de dejar al descubierto los tesoros novohispanos, sino porque las grandes extensiones y sus necesidades de protección terminarían dejando grandes vacíos de poder y de territorio.

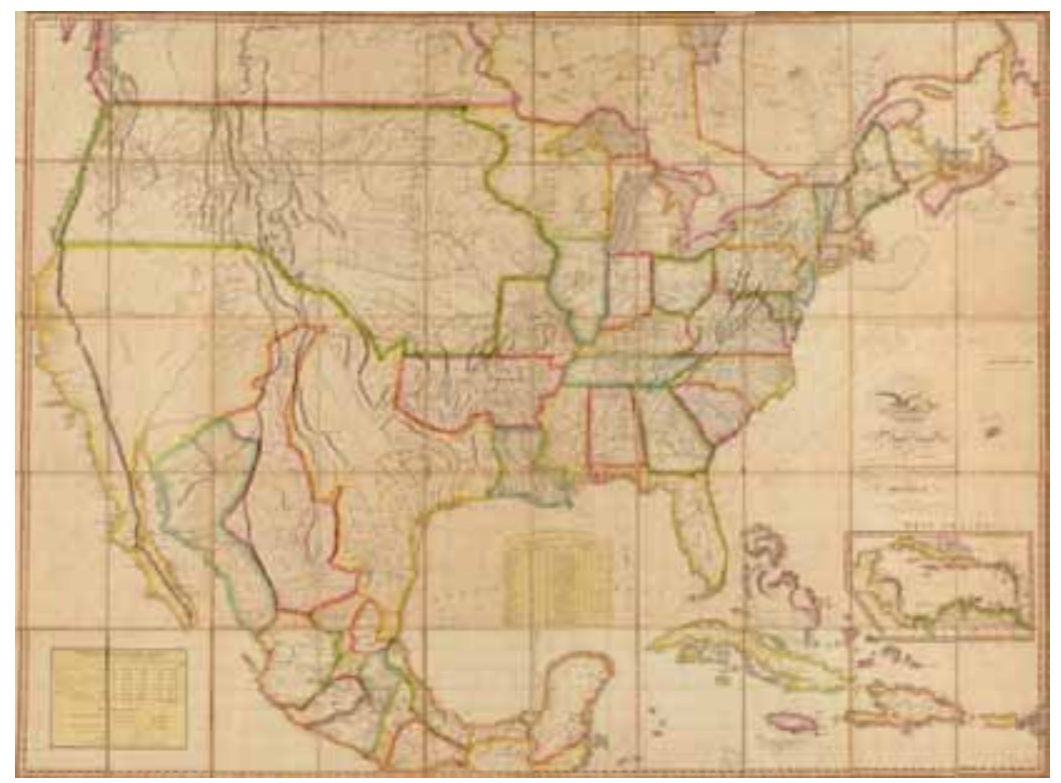

Figura $N^{\circ}$ 9. John Melish et al. Map of the United States of America...

Fuente: Melish, John, J. Vallance, and Henry Schenck Tanner. Map of the United States of America: with the contiguous British \& Spanish possessions. Philadelphia: John Melish, 1820. En Library of Congress, www.loc.gov/item/2008622175, consultado el 29-X-2020.

La revisión de los mapas a partir de la representación de audiencias y provincias nos advierte de un gran silencio por parte de la Monarquía católica española, como lo muestran los casos de Juan López de Velasco y, posteriormente, de Villaseñor y Sánchez, cuyas obras serían práctica- 
mente guardadas como secreto de Estado, la primera hasta el siglo XIX y la segunda hasta principios del siglo XX (Antochiw, 2000: 74). No obstante, los cartógrafos ingleses, franceses y holandeses, principalmente, pudieron reconstruir las divisiones antiguas como una manera de reconocer la construcción del espacio a través de divisiones territoriales de las patrias que serían reivindicadas, con ayuda de estas nuevas potencias, al momento del colapso de la Monarquía hispana. Ciertamente, no se trató del nacionalismo, cuya legitimidad provenía de la construcción misma de una nación de ciudadanos, pero sí de un patriotismo que tuvo sus raíces en la territorialidad construida históricamente. De ahí que, de acuerdo con Benedict Anderson, los inventores del patriotismo fueron los "pioneros criollos", al reconstruir la patria frente a la nación.

Las aportaciones, en especial de Humboldt, a la cartografía mexicana han sido parte de una polémica más amplia sobre el uso de la información, ciertamente estratégica, como por ejemplo sobre las minas y sobre las provincias internas. Humboldt entregó primeramente la información al rey Carlos IV y al virrey Iturrigaray, información que se pensaba perdida y que hasta muy recientemente se ha catalogado en la Real Academia de Historia (Manso Porto, 2008). Por otra parte, al momento de la venta de las Floridas por parte de España a los Estados Unidos, en 1819, el mapa utilizado fue el de John Melish y no el de Humboldt, por lo que habría que pensar a Humboldt a partir del difícil equilibrio entre inteligencia y poder, especialmente en una época caracterizada por la censura, en que Humboldt era prácticamente el único investigador autónomo.

\section{Reflexiones finales}

A partir de las nuevas perspectivas historiográficas sobre el espacio y el territorio, de la renovación de la geografía y de la historia del Derecho, la lectura de los mapas sobre la Nueva España en particular nos advierte de una ausencia o de un silencio que no sería sino hasta Humboldt y posteriormente hasta Edmundo O'Gorman que se le conociera. Se trata de la "división antigua", referida por Humboldt como la más usada pero muy poco conocida. Esta división, conformada por las provincias, nos muestra no solo las políticas o "prácticas de reserva" de la Monarquía católica, es decir, la estrategia de ocultar los conocimientos frente a sus enemigos, sino también una concepción del poder y del territorio 
más bien fragmentada y que tiene que ver con la Monarquía compuesta o pluricéntrica, en la cual las representaciones que predominan son las costas, las bahías y puertos, así como los pueblos, villas y ciudades o provincias aisladas, pero no un mapa integrado del territorio en provincias. No sería sino hasta el mapa elaborado por Humboldt al conde de la Valenciana, en 1804, que se tendría una Carta General, la cual recientemente ha sido descubierta en la Colección Humboldt de la Academia de la Historia de España. Se trata de una Carta General que da cuenta de una conformación territorial de viejo cuño y que tendría su expresión al momento de la independencia, de ahí lo peculiar de la conformación territorial de los Estados de la república, a diferencia de lo ocurrido con los vecinos del norte.

El mapa proyectado por Jefferson y Harthley (1783), junto con la Ordinance for the Government of the Territory of the Unites States, de 1787, fueron la representación de un nuevo tipo de territorialidad, basada en una idea de planeación "racional" como si el territorio estuviera vacío, como si fuera desde una tabula rasa, sin todos los andamiajes del Viejo Mundo o de los intereses de una sociedad corporativa. El mapa de Jefferson fue un mapa que imaginó el futuro crecimiento de los diferentes Estados de la unión en el noroeste americano, al mismo tiempo que propició la normatividad para la apropiación de los amplios espacios en la frontera del oeste, uniendo con ello la idea de "ciudadanía" con el derecho de propiedad y dando lugar a otra forma de territorialidad (Schlögel, 2003: 175-186).

La organización territorial de la Nueva España, en contraste, se fue construyendo a partir de los reinos prehispánicos, pero sobre todo con base en la gratificación a encomenderos y capitanes de guerra en los orígenes de la colonización, lo cual, en el siglo XVII, permitiría la expansión de los latifundios y de pueblos, villas y ciudades; también, a partir de las mercedes otorgadas por la corona y la jurisdicción de las audiencias en la conformación de las provincias. No fue ciertamente una planeación central para la creación de una federación, sino una respuesta más pragmática al proceso mismo de colonización. La territorialidad se configuró a partir de instituciones castellanas que venían de la Baja Edad Media que, si bien se adaptaron, incluso con un mayor grado de autonomía como las audiencias, replicaron las formas de dominio de la Monarquía católica. 
De ahí que no sería sino hasta prácticamente Humboldt que se conocería a la Nueva España con todas sus provincias, o de todos los reinos americanos, ya que, además de las razones de seguridad y defensa, de las "prácticas de reserva", la concepción territorial de la Monarquía tenía que ver más con la administración de justicia, con los ministros de las audiencias y con la concesión de mercedes que con la generación de nuevas leyes para colonizar desde la propiedad privada. Las reformas borbónicas trataron de reorganizar el espacio geopolítico, pero implicaron fundamentalmente el reconocimiento de las provincias en intendencias. De ahí que, finalmente, prevalecería para el México independiente la "división antigua" que se configuró desde el proceso de colonización, la cual fue reconocida por las Cortes de Cádiz con una diferencia: la ruralización de la política al aceptar la expansión de las municipalidades y, a partir de ello, la generación de tensiones estructurales entre las diferentes soberanías reconocidas, dificultando con ello la conformación del Estado nación.

\section{Referencias bibliográficas}

\section{Fuentes primarias}

\section{a) Recursos cartográficos}

Aa, P. van der. (1714). Nouvel Atlas, tres-exact et fort commode pour toutes sortes de personnes, Contenant les Principales Cartes Geographiques. Leiden: Phillips, Geographical Atlases, Vol. IV, title 4277.

Arrowsmith, A. (s/f). "Chart of the West Indies and Spanish Dominions in North America". London: A. Arrowsmith.

Humboldt, Alexander von (2003). Atlas Geográfico y Físico del Reino de la Nueva España. Ciudad de México: Siglo XXI Editores.

Fuentes secundarias

a) Artículos y capítulos de libros

Álvarez, S. (2011). "Patrimonio territorial y fronteras: la visión del estado mexicano en el siglo XIX", en C. Herrejón Peredo (ed.) $L a$ formación geográfica de México. Ciudad de México: CONACULTA, pp. 70-125. 
Antochiw, M. (2000). "La Visión total de la Nueva España. Los Mapas generales del siglo XVIII", en H. Mendoza Vargas (ed.) México a través de los Mapas. Ciudad de México: UNAM/Plaza y Valdés, pp. 71-88.

Berthe, J.-P. (1998). “Juan López de Velasco (ca. 1530-1598). Cronista y Cosmógrafo Mayor del Consejo de Indias: Su personalidad y su obra geográfica”, en Relaciones, Vol. XIX, N 75, pp. 143-72.

Brunner, O. (1976). “La 'Casa Grande’ y la 'Oeconomica' de la vieja Europa”, en Nuevos caminos de la historia social y constitucional. Buenos Aires, Argentina: Editorial Alfa, pp. 87-123.

Buisseret, D. (2005). "Spanish Military Engineers in the New World before 1750", en D. Reinhartz y G. D. Saxon (eds.) Mapping and Empire: Soldier-Engineers on the Southwestern Frontier. Austin, TX: University of Texas Press, pp. 44-56.

Carmagnani, M. (1984). “Territorialidad y Federalismo en la formación del Estado mexicano", en Problemas de la Formación del Estado y de la Nación Hispanoamericana. Böhlau Verlag Köln Wien, pp. 289-304.

Codding, M. A. (1994). “Mapping Mexico. Perfecting the geography of New Spain: Alzate and the Cartography Legacy of Siguenza y Góngora”, en Colonial Latin American Review, № 3 , pp. 185-219.

Commons, A. (1989). "La División territorial del Segundo Imperio mexicano, 1865", en Estudios de Historia Moderna y Contemporánea de México, №12, pp. 79-98.

Cramaussel, C. (1998). “Un desconocimiento peligroso: La Nueva Vizcaya en la cartografía y los grandes textos europeos de los siglos XVI y XVII", en Relaciones, Vol. XIX, N 75, pp. 175-211.

Del Vas Mingo, M. M. (1999). "La problemática de la ordenación territorial en Indias (ss. XVI-XVIII)", en Revista Complutense de Historia de América, pp. 67-98.

Diego-Fernández Sotelo, R. (1998). “Consideraciones en torno al problema jurisdiccional en el periodo colonial", en Anuario Mexicano de Historia del Derecho, pp. 277-88.

Diego-Fernández Sotelo, R. y M. P. Gutiérrez Lorenzo (2014). “Genealogía del proyecto borbónico. Reflexiones en torno al tema de las Subdelegaciones”, en R. Diego-Fernández Sotelo, M. P. Gutiérrez Lorenzo y L. A. Arroja Díaz Vituell (eds.) De Reinos y Subdelegaciones. Nuevos escenarios para un nuevo orden 
en la América borbónica. El Colegio de Michoacán/Universidad de Guadalajara/El Colegio Mexiquense, pp. 17-51.

Dym, J. (2010). "Presentación: Mapeando patrias chicas y patrias grandes: cartografía e historia iberoamericana, siglos XVIII-XX", en Araucaria. Revista Iberoamericana de Filosofía, Política y Humanidades, $\mathrm{N}^{\circ} 12$, pp. 99-109.

Garriga, C. (2004). "Orden jurídico y poder político en el Antiguo Régimen", en Istor. Revista de Historia Internacional, $\mathrm{N}^{\circ} \mathrm{IV}$, pp. 2-21.

Harley, J. B. (2005). "Silencios y secretos. La agenda oculta de la cartografía en los albores de la Europa moderna", en P. Laxton y J. H. Andrews (eds.) La Nueva naturaleza de los mapas. Ensayos sobre historia de la cartografía. Ciudad de México: Fondo de Cultura Económica, pp. 113-140.

Hespanha, A. M. (1993). "El espacio político", La Gracia del derecho. Economía de la cultura en la Edad Moderna. Madrid, España: Centro de Estudios Constitucionales, pp. 85-122.

Hillerkuss, T. (2013). "Las minas de la Nueva España en los mapas del siglo XVI. ¿Un secreto de Estado?", en Apuntes. Revista de estudios sobre patrimonio cultural, $\mathrm{N}^{\circ} 26$, pp. 10-25.

Manso Porto, C. (2008). "La Colección cartográfica de América de Alexander von Humboldt conservada en la Real Academia de Historia", en Boletín de la Real Academia de la Historia, Vol. CCV, pp. 537-89.

Moncada Maya, J. O. (2009). "Construyendo el territorio. El desarrollo de la cartografía en Nueva España", en H. Mendoza Vargas y C. Lois (eds.) Historias de la Cartografía de Iberoamérica. Nuevos caminos, viejos problemas. Ciudad de México: UNAM/INEGI, pp. 161-182.

Reinhartz, D. (2005). "Spanish military Mapping of the Northern Bordelands after 1750", en D. Reinhartz y G. D. Saxon (eds.) Mapping and Empire: Soldier-Engineers on the Southwestern Frontier. Austin, TX: University of Texas Press, pp. 57-79.

Rojas, B. (1999). “Cartografía ¿para qué? Nueva España 1725-1800”, en Relaciones, Vol. 20, Nㅜㄱ, pp. 219-47.

Sack, R. D. (1991). "El Significado de la Territorialidad", en P. Pérez Herrero (ed.) Región e Historia en México (1700-1850). Ciudad de México: Instituto Mora/Universidad Autónoma Metropolitana, pp. 194-204. 
Soja, E. W. (2010). “Tercer espacio: extendiendo el alcance de la imaginación geográfica", en A. Albet y N. Benach (eds.) La perspectiva postmoderna de un geógrafo radical. Barcelona, España: Icaria Editorial, pp. 181-209.

Tau Anzoátegui, V. (2000). “Las Indias ¿Provincias, reinos o colonias? A propósito del planteo de Zorraquín Becú",en Revista de Historia del Derecho, pp. 77-138.

Trabulse, E. (2001). "La obra cartográfica de don Carlos de Sigüenza y Góngora”, en Caravelle C.M.H.L.B., pp. 265-75.

\section{b) Libros}

Annino, A. (2015). Silencios y disputas en la historia de Hispanoamérica. Ciudad de México: Taurus.

Borah, W. et al. (1985). El Gobierno provincial en la Nueva España 1570-1787. Ciudad de México: Universidad Nacional Autónoma de México.

Cardim, P., T. Herzog, J. J. Ruiz Ibáñez \& G. Sabatini (2014). Polycentric Monarchies. How did Early Modern Spain and Portugal Achieve and Maintain a Global Hegemony? Sussex Academy e-Library.

Gerhardt, P. (1996). La Frontera norte de la Nueva España. Ciudad de México: Universidad Nacional Autónoma de México.

Humboldt, Alejandro de (2002). Ensayo Político sobre el Reino de la Nueva España. Ciudad de México: Editorial Porrúa.

León-Portilla, M. (2001). Cartografía de la Antigua California. Ciudad de México: Universidad Nacional Autónoma de México.

López de Velasco, J. (1894). Geografía y Descripción Universal de las Indias. Madrid, España: Real Academia de la Historia/Establecimiento Tipográfico de Fortanet.

Mantilla Trolle, M., R. Diego-Fernández Sotelo y A. Moreno Torres (2008). Actores Regionales de las Reformas Borbónicas. Real Ordenanza para el establecimiento é instrucción de intendentes de exército y provincia en el reino de la Nueva España. Edición anotada de la Audiencia de la Nueva Galicia, edición y estudios. El Colegio de Michoacán/Universidad de Guadalajara/El Colegio de Sonora.

O'Gorman, E. (2000). Historia de las divisiones territoriales de México. Ciudad de México: Editorial Porrúa. 
Pietschmann, H. (2011). ¿Hasta qué grado conoció Humboldt la Nueva España? Ciudad de México, México: UNAM.

Sánchez Lamego, M. A. (1955). El Primer Mapa General de México elaborado por un mexicano. Ciudad de México: Instituto Panamericano de Geografía e Historia.

Saquet, M. A. (2015). Por una geografía de las territorialidades y de las temporalidades. Una concepción multidimensional orientada a la cooperación y el desarrollo territorial. Buenos Aires, Argentina: Universidad Nacional de la Plata.

Schlögel, K. (2003). En el espacio leemos el tiempo. Sobre historia de la civilización y geopolítica. Madrid, España: Ediciones Siruela.

Trabulse, E. (1983). Cartografía mexicana. Tesoros de la nación. Siglos XVI al XIX. Ciudad de México: Archivo General de la Nación.

Villaseñor y Sánchez, J. A. de (1992). Theatro americano. Descripción general de los Reynos y Provincias de la Nueva España y sus jurisdicciones. Ciudad de México: Editorial Trillas. 